\title{
A novel tandem differential mobility analyzer with organic vapor treatment of aerosol particles
}

\author{
J. Joutsensaari ${ }^{1}$, P. Vaattovaara ${ }^{1}$, M. Vesterinen ${ }^{1}$, K. Hämeri ${ }^{2}$, and A. Laaksonen ${ }^{1}$ \\ ${ }^{1}$ Department of Applied Physics, University of Kuopio, P.O. Box 1627, FIN-70211 Kuopio, Finland \\ ${ }^{2}$ Finnish Institute of Occupational Health, Topeliuksenkatu 41 a A, FIN-00250 Helsinki, Finland \\ Received 2 July 2001 - Published in Atmos. Chem. Phys. Discuss. 3 September 2001 \\ Revised 4 December 2001 - Accepted 5 December 2001 - Published 14 December 2001
}

\begin{abstract}
A novel method to characterize the organic composition of aerosol particles has been developed. The method is based on organic vapor interaction with aerosol particles and it has been named an Organic Tandem Differential Mobility Analyzer (OTDMA). The OTDMA method has been tested for inorganic (sodium chloride and ammonium sulfate) and organic (citric acid and adipic acid) particles. Growth curves of the particles have been measured in ethanol vapor and as a comparison in water vapor as a function of saturation ratio.
\end{abstract}

Measurements in water vapor show that sodium chloride and ammonium sulfate as well as citric acid particles grow at water saturation ratios $(S)$ of 0.8 and above, whereas adipic acid particles do not grow at $S<0.96$. For sodium chloride and ammonium sulfate particles, a deliquescence point is observed at $S=0.75$ and $S=0.79$, respectively. Citric acid particles grow monotonously with increasing saturation ratios already at low saturation ratios and no clear deliquescence point is found.

For sodium chloride and ammonium sulfate particles, no growth can be seen in ethanol vapor at saturation ratios below 0.93. In contrast, for adipic acid particles, the deliquescence takes place at around $S=0.95$ in the ethanol vapor. The recrystallization of adipic acid takes place at $S<0.4$. Citric acid particles grow in ethanol vapor similarly as in water vapor; the particles grow monotonously with increasing saturation ratios and no stepwise deliquescence is observed.

The results show that the working principles of the OTDMA are operational for single-component aerosols. Furthermore, the results indicate that the OTDMA method may prove useful in determining whether aerosol particles contain organic substances, especially if the OTDMA is operated in parallel with a hygroscopicity TDMA, as the growth of many

Correspondence to: A. Laaksonen (ari.laaksonen@uku.fi) substances is different in ethanol and water vapors.

\section{Introduction}

To understand global climate change and health risks caused by aerosols in detail, better understanding of chemical and physical processes of aerosol particles in the atmosphere is needed. These processes depend on the chemical composition and properties (e.g. hygroscopic properties) of the individual aerosol particles. Organic matter is a significant or sometimes dominating fraction of submicron atmospheric aerosol particles, e.g. over continental region, it typically represents $20-50 \%$ of total fine particle mass (Saxena and Hildemann, 1996). Obviously, the organic particulate matter can also influence the radiation balance of the Earth (Novakov and Penner, 1993). However, the chemical composition of aerosol particles, especially those in the $50 \mathrm{~nm}$ range and below, is difficult to determine because of their small mass, which necessitates long collection times at ambient conditions. Therefore, there is a need to develop novel methods to determine the organic content of atmospheric aerosols.

Tandem Differential Mobility Analyzers (TDMA) (Liu et al., 1978) are nowadays popular instruments for characterizing atmospheric and laboratory aerosols according to their hygroscopicity or volatility. The hygroscopic properties of ambient aerosol particles have been studied in numerous field studies (e.g., McMurry and Stolzenburg, 1989; Zhang et al., 1993; Svenningsson et al., 1997; Swietlicki et al., 1999; Hämeri et al., 2001a). The experiments show that the atmospheric particles can be classified to more-hygroscopic and less-hygroscopic groups according to their hygroscopic properties, i.e. different growth factors in water vapor. The atmospheric particles often contain both hygroscopic compounds (e.g. inorganic salts) and insoluble materials (e.g. 
Table 1. Rough categorization of different substances found in aerosol particles based on their growth factors in water (i.e. HTDMA) and organic solvent (ethanol) vapor (i.e. OTDMA)

\begin{tabular}{lcc}
\hline Substance & $\begin{array}{r}\text { Growth factor } \\
\text { in water vapor }\end{array}$ & $\begin{array}{c}\text { Growth factor } \\
\text { in ethanol vapor }\end{array}$ \\
\hline Inorganic salts & $>1$ & 1 \\
$\begin{array}{l}\text { Water-insoluble organics } \\
\text { Water-soluble organics, }\end{array}$ & $>1$ & $>1$ \\
sulfuric acid & 1 & $>1$ \\
$\begin{array}{l}\text { Elemental carbon, } \\
\text { ethanol-insoluble organics, } \\
\text { minerals }\end{array}$ & & \\
\hline
\end{tabular}

water insoluble organic compounds). In the laboratory experiments, TDMA techniques have been used to determine the growth factors of compounds commonly found in the atmosphere, e.g. sodium chloride and ammonium sulfate (McMurry and Stolzenburg, 1989; Svenningsson, 1997; Hansson et al., 1998). Recently, we have demonstrated the capability of an Ultrafine TDMA method for measuring the hygroscopicity of particles as small as $8 \mathrm{~nm}$ in diameter (Hämeri et al., 2000, 2001b). Furthermore, we have used TDMA techniques for studying a development of a crystal habit and evaporation of solid titanium dioxide and fullerene aerosol particles (Ahonen et al., 2001; Joutsensaari et al., 2000).

TDMA's provide indirect information about the chemical composition of aerosols, even when the concentration or size of the particles is too small for actual chemical analysis. However, the information provided by a TDMA is limited: e.g. the hygroscopicity TDMA (HTDMA) makes no difference between different water insoluble compounds (e.g. elemental carbon and water insoluble organic species). In this paper, we present a novel TDMA device which, when operated in parallel with a HTDMA, can overcome this problem. We have named the new device the Organic Tandem Differential Mobility Analyzer (OTDMA).

The idea of the OTDMA is to treat monodisperse aerosol particles with subsaturated organic vapor and to detect the size change of the particles as they dissolve and take up vapor molecules. The behavior of soluble particles in the OTDMA is expected to be analogous to that observed in an HTDMA. Thus, the growth factor (Swietlicki et al., 1999) of a dry particle in the OTDMA is expected to be unity up to the deliquescence saturation ratio, at which point the particle is dissolved and becomes a droplet composed of a saturated solution. After the deliquescence point, the growth factor is expected to increase with increasing vapor saturation ratio. Different organic solvents will naturally exhibit different deliquescence saturation ratios and produce different growth factors for a given aerosol type.

We chose the organic solvent used in the first version of the OTDMA to be ethanol. According to the CRC Handbook of Chemistry and Physics (1995), ethanol is a fairly universal organic solvent, and therefore a good candidate for a substance that can be used to detect particles containing organic compounds. On the other hand, the most common salts that can be found in atmospheric aerosols (e.g. ammonium sulfate and sodium chloride) are not soluble in ethanol. This is a useful property, since it allows making a rough categorization of different substances found in aerosol particles based on their growth factors in HTDMA and OTDMA (see Table 1). Further advantages of ethanol are that it is not very toxic even at fairly high quantities, and that its saturated vapor is not explosive at normal conditions.

In this paper, we describe construction of the OTDMA and present results of laboratory tests for some organic (citric acid and adipic acid) and inorganic (sodium chloride and ammonium sulfate) aerosol particles. To our knowledge, the operation of a TDMA method with an organic solvent treatment of aerosol particles has not been reported so far. This paper is organized as follows. In the Sect. 2 we present the details of the operating principles of the OTDMA, which was designed so that it can also be operated as a HTDMA by changing the particle treatment unit. Section 3 outlines the theory describing particle growth in subsaturated solvent vapors. In Sect. 4 we show measured growth curves of selected substances both in ethanol and water vapor as a function of saturation ratio, demonstrate that the working principles of the OTDMA are operational and discuss the results. Finally, the conclusions are given in Sect. 5.

\section{Experimental}

\subsection{Setup of the organic TDMA}

Figure 1 shows a schematic diagram of the organic TDMA system. The operation principle of the OTDMA is basically similar to the hygroscopicity TDMA (e.g., Hämeri et al., 2000) with the difference that the size-classified aerosol is carried through an organic solvent vapor instead of water vapor. In the experiments presented in this paper we used ethanol vapor as the organic solvent. In the OTDMA system, the first differential mobility analyzer (DMA-1, Hauke type, length $28 \mathrm{~cm}$ (Winklmayr et al., 1991)) was used to classify a monodisperse fraction of the aerosol particles based on their electrical mobility. The particles were passed to the DMA-1 through a neutralizer (Ni-63 radioactive $\beta$-source). A sample flow of 1 1/min was used. A dry (relative humidity, RH 3\%) and clean air flow of $10 \mathrm{l} / \mathrm{min}$ was used as sheath and excess flow in the DMA-1 (aerosol - sheath flow ratio 1:10). The sheath and excess flows were controlled by critical orifices. One primary (dry) particle diameter of $100 \mathrm{~nm}$ was used in the experiments.

The change in particle size due to interaction with the ethanol vapor was determined with the second DMA (DMA- 


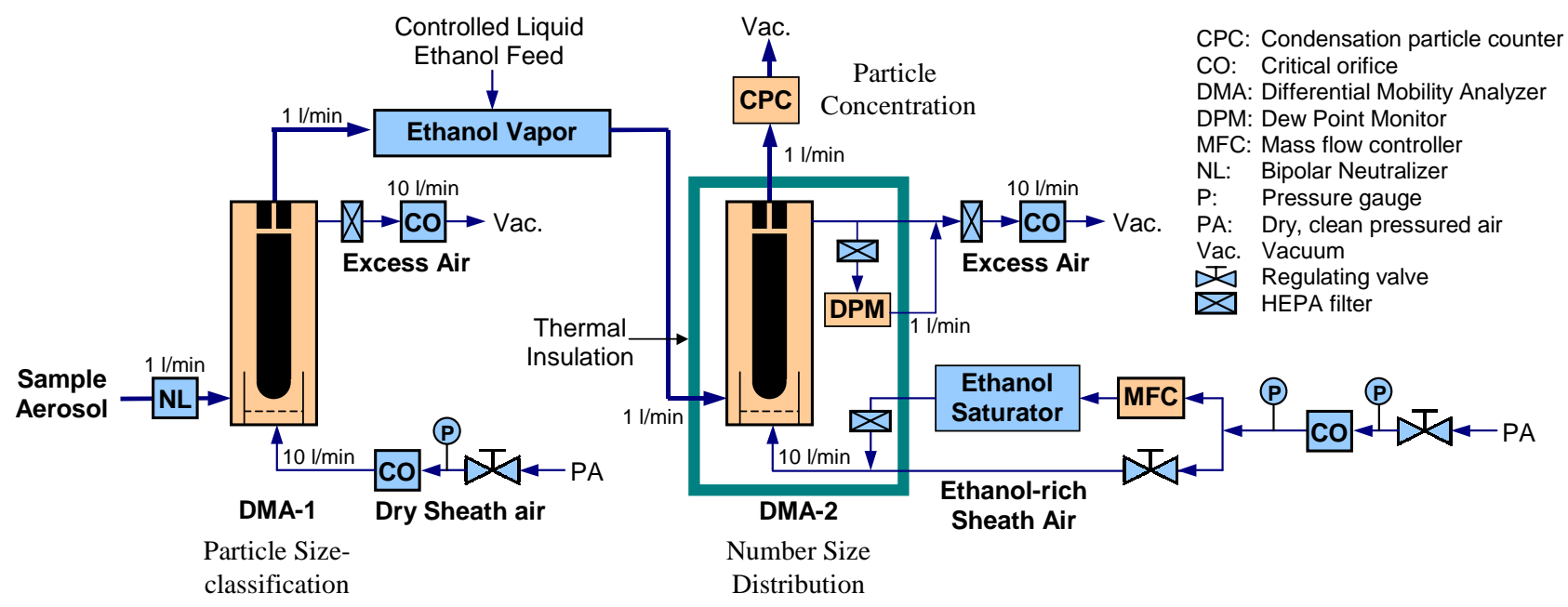

Fig. 1. Schematic of an Organic Tandem Differential Mobility Analyzer (OTDMA) setup for measuring organic composition of aerosol particles.

2, similar to DMA-1) by measuring the particle number size distribution. The aerosol was not neutralized anymore before the DMA-2. The DMA-2 was operated with aerosol and sheath flows of 1 and $10 \mathrm{l} / \mathrm{min}$, respectively (aerosol sheath flow ratio 1:10). The sheath and excess flows were controlled by critical orifices. The particle number concentrations after DMA-2 were determined with a condensation particle counter (CPC, TSI 3010), which provided the sample flow of $1 \mathrm{l} / \mathrm{min}$ through the OTDMA. The number size distributions were calculated using a standard DMA data inversion algorithm (Reischl, 1991; Knutson and Whitby, 1975). To determine growth factors (diameter at certain saturation ratio/ dry diameter) of the particles, the geometric number mean diameter of the size distribution was used as an average particle size in the calculations. For bimodal distributions, the geometric number mean diameters and growth factors were determined separately for both modes (modes for increasing and decreasing saturation ratios) by fitting two lognormal size distributions to the experimental data.

A controlled concentration of ethanol vapor was set to the sheath air flow of DMA-2 in order to treat particles with ethanol vapor and also to avoid ethanol evaporation from the particles inside DMA-2 during the measurements. In the experiments for citric acid particles, the aerosol particles were only treated by ethanol-rich sheath air flow. In that case the interaction between aerosol particles and ethanol vapor takes place only inside the DMA-2. According to data for hygroscopic growth (Kerminen, 1997), it can be estimated that the particles grow to equilibrium size inside DMA-2 within no more than a few milliseconds which is a very short time compared to the particle residence time of about 2 seconds inside the DMA. Ethanol saturation ratio of the DMA-2 sheath flow was controlled by mixing ethanol-saturated (saturation ratio $\sim 1$ ) and dry air streams (saturation ratio $\sim 0$ ). The ethanol- saturated air is produced by bubbling dry air through heated $\left(\sim 28^{\circ} \mathrm{C}\right)$ liquid ethanol (purified, absoluted ethanol, purity $>99.5$ weight- $\%$, Primalco Ltd., Finland) and it was filtered with a HEPA (High Efficiency Particulate-free Air) capsule (Pall Gelman) after the saturator. The air flow rate to the ethanol saturator was controlled by a mass flow controller (Brooks Instrument, Model 5850S). To determine ethanol vapor saturation ratio, the dew point of the ethanol vapor was measured with a dew point monitor (General Eastern, Hygro M4 with Model D-2 Chilled Mirror Sensor, accuracy $\pm 0.2^{\circ} \mathrm{C}$ for water vapor) from a fraction $(1 \mathrm{l} / \mathrm{min})$ of the excess air of the DMA-2. In addition to determining relative humidity of air, the dew point monitor can be used to measure the saturation ratio for different pure vapors such as ethanol (Schultz, $2000)$. The saturation ratio $(S)$ of the ethanol vapor was calculated from the dew point and the air temperatures of the excess flow using the ethanol vapor pressure data by Schmeling and Strey (1993), i.e. $S=$ saturation vapor pressure at dew point / saturation vapor pressure at excess air temperature. We estimated that the accuracy of the measurement of $S$ is about $\pm 2 \%$-units for ethanol vapor.

For adipic acid particles, an external aerosol treatment unit was used before DMA-2 to produce high enough ethanol saturation ratios for particle growth. The aerosol treatment unit was also used to introduce ammonium sulfate and sodium chloride particles to ethanol sturation ratios close to unity. Two different types of the unit were used. In one one of the units, particles were passed through ethanol vapor produced by evaporating liquid ethanol (purified, absoluted ethanol, purity $>99.5$ weight- $\%$ ) on a heated surface inside the sampling tubing. The heated surface was covered with a glass fiber tube. To evaporate ethanol, the surface temperature of the ethanol evaporator was kept at $40-60^{\circ} \mathrm{C}$ with a PID temperature controller. The liquid ethanol was fed onto the 
heated surface by a syringe pump (Hostec R-50, Finland), and the saturation ratio of the ethanol vapor was roughly controlled by the feed rate of the liquid ethanol. We estimated that the accuracy of the ethanol saturation ratio in the aerosol air flow is about $\pm 5 \%$-units for that unit. In some experiments we used a GoreTex tube (model TA005, ultra flexible, inner diameter $5 \mathrm{~mm}$, Creative Technologies Worldwide, Japan) ethanol treatment unit similar to that used for water vapor. The ethanol saturation ratio was roughly controlled by temperature of the air inside the GoreTex tube. The unit was calibrated with the dew point monitor. During the experiments, however, liquid ethanol was found inside the tubing indicating that the liquid ethanol was passed through the GoreTex tube. We estimated that the accuracy of the ethanol saturation ratio is about $\pm 10 \%$-units for that unit.

To determine the hysteresis curve between particle deliquescence and recrystallization saturation ratios, both increasing and decreasing saturation ratio curves were measured (the increasing curve refers to the lower branch and the decreasing curve to the upper branch of the hysteresis loop). The volume of the aerosol flow is $10 \%$ of the sheath air flow, and if the aerosol flow is completely free of solvent vapor, the maximum increasing saturation ratio that can be reached inside DMA 2 is 0.91 (corresponding to completely saturated sheath air). In order to make sure that we are on the lower branch of the hysteresis curve, we have to keep the saturation ratio of the aerosol flow below that of the sheath air, and in order to locate the deliquescence point, the $S$ of the aerosol flow has to be below the deliquescence saturation ratio. In case of ethanol vapor, the uncertainty of the saturation ratio in the external aerosol treatment unit (see above) prevented us from reaching increasing saturation ratios higher than 0.95 inside DMA 2 (i.e. we had to keep the saturation ratio of the aerosol flow low enough to make sure that it does not accidentally become higher than that of the sheath air). When measuring the upper branch of the hysteresis curve, the aerosol flow has a higher saturation ratio than the sheath air. In these measurements the $S$ of the aerosol flow can be kept close to unity, and thus it is possible to reach a higher $S$ inside DMA 2 than in the increasing saturation ratio measurements, but we were still limited to $S=0.97-0.98$. Note that these are exceptionally high values and rarely seen in measurements with water vapor; at high saturation ratios there is always the danger that temperature fluctuations somewhere inside the DMA apparatus cause the saturation ratio to reach unity. This results in condensation on the walls of the apparatus, and the released heat will change the conditions from those that were intended. Also, measurement of saturation ratio becomes more uncertain as it approaches unity.

The flow rates of both DMAs were measured frequently using a bubble flow meter (Gillian Gilibrator 2, Sensidyne, USA, accuracy 1\%). Furthermore, the ethanol-rich sheath and excess flows were adjusted to be equal on DMA-2 after ethanol saturation ratio was changed.

In order to keep the DMA-2 at a constant temperature, it was covered with tubing containing circulating water from a temperature controlled water bath (Lauda RE 104, Lauda Dr. R. Wobser GmbH \& Co. KG, Germany, temperature control $\pm 0.05^{\circ} \mathrm{C}$ ). Additionally, the DMA-2 was thermally insulated. The temperature of DMA- 2 was kept at $23^{\circ} \mathrm{C}$ during the measurements. Temperatures of aerosol, sheath and excess air flows were monitored with temperature sensors (Pt100, accuracy $\pm 0.4^{\circ} \mathrm{C}$ for aerosol and sheath flows and $\pm 0.15^{\circ} \mathrm{C}$ for excess flow). The temperatures were typically within $0.3^{\circ} \mathrm{C}$ during the experiments.

Because ethanol is easily flammable, it ignites to burn in air if a spark takes place inside the DMA-2 at high center rod voltages (i.e. large particle diameters). During measurements with high rod voltages, the instrument must be supervised at all times and the feeding of the ethanol vapor must be stopped immediately after a spark. The ignition of ethanol can be prevented using an inert gas, e.g. nitrogen, for the sheath flows of the DMAs.

\subsection{Hygroscopicity TDMA}

Hygroscopic properties of the test aerosols were determined with a hygroscopicity TDMA. The HTDMA instrument was set up by changing the aerosol particle treatment and the sheath air saturator units of the OTDMA system. The aerosol and sheath air flows were humidified with humidifiers based on use of GoreTex tube (model TB005, ultra flexible, inner diameter $5 \mathrm{~mm}$, Creative Technologies Worldwide, Japan) in a water bath. The humidifiers are described in detail elsewhere (Hämeri et al., 2000). The relative humidities of aerosol and sheath air flows were detected with relative humidity (RH) sensors (Vaisala Humicap 180; Finland; accuracy: $0-90 \% \mathrm{RH} \pm 2 \% \mathrm{RH}, 90-100 \% \mathrm{RH} \pm 3 \% \mathrm{RH})$ and controlled with PID controllers. Relative humidity of the excess air flow was detected with a dew point monitor (General Eastern, Hygro M4, accuracy $\pm 1 \%$ ). To determine hysteresis between particle deliquescence $\mathrm{RH}$ and recrystallization $\mathrm{RH}$, both increasing and decreasing saturation ratio curves were measured. The RH of aerosol flow was kept about 2 $3 \%$-units lower that that of sheath flow for measurements with increasing water saturation ratios. For measurements with decreasing saturation ratios, the $\mathrm{RH}$ of aerosol flow was kept about 3\%-units higher than the value of deliquescence point.

\subsection{Test aerosols}

Inorganic ammonium sulfate $\left(\left(\mathrm{NH}_{4}\right)_{2} \mathrm{SO}_{4}\right.$, FF-Chemicals, Finland, purity $>99 \%$ ) and sodium chloride $(\mathrm{NaCl}$, FFChemicals, Finland, purity $>99.8 \%$ ), and organic citric acid $\left(\mathrm{C}_{6} \mathrm{H}_{8} \mathrm{O}_{7} \cdot \mathrm{H}_{2} \mathrm{O}\right.$, Fisher Chemicals, UK, purity $\left.99.92 \%\right)$ and adipic acid $\left(\mathrm{C}_{6} \mathrm{H}_{10} \mathrm{O}_{4}\right.$, Merck-Schuchardt, Germany, purity $>99 \%$ ) particles were used as test particles. The test particles were generated from aqueous precursor solutions. The precursor solutions of $500 \mathrm{ml}$ were prepared by mixing the 
Table 2. Values used in the theoretical calculations (CRC Handbook of Chemistry and Physics, 1995).

\begin{tabular}{lccc}
\hline Substance & $\begin{array}{c}M_{d} \\
\mathrm{~g} / \mathrm{mol}\end{array}$ & $\begin{array}{c}\rho_{d} \\
\mathrm{~g} / \mathrm{cm}^{3}\end{array}$ & $\begin{array}{c}\rho_{s} \\
\mathrm{~g} / \mathrm{cm}^{3}\end{array}$ \\
\hline Sodium chloride & 58.44 & 2.165 & \\
Ammonium sulfate & 132.14 & 1.769 & \\
Citric acid & 192.14 & 1.665 & \\
Adipic acid & 146.14 & 1.36 & \\
Water & 18.02 & & 1.0 \\
Ethanol & 46.07 & & 0.7893 \\
\hline
\end{tabular}

powder and deionized, distilled water and stirring the suspensions until the powder was completely dissolved. Precursor solution concentrations of $0.8 \mathrm{M}$ for ammonium sulfate, $1 \mathrm{M}$ for sodium chloride, $0.09 \mathrm{M}$ for citric acid and $0.06 \mathrm{M}$ for adipic acid were used in this study. The precursor solutions were atomized by a constant output atomizer (TSI 3076 type, TSI Inc., USA) with a dry air flow of $3 \mathrm{l} / \mathrm{min}$. Immediately after the generator, the aerosol was diluted with a dry (RH $\sim 3 \%$ ) air flow of about 25 1/min (dilution ratio 1:9). During the dilution the water was evaporated from the atomized droplets thus forming solid particles. A flow fraction of 1 1/min was taken to the DMA-1 as an aerosol sample flow. Some additional experiments for citric acid were carried out using a diffusion dryer (Silica gel desiccant surrounding the air flow) before the DMA-1. During those experiments, $\mathrm{RH}$ of the aerosol flow was $1-4 \%$.

\section{Theory}

In this section, we present the theory of deliquescent growth of aerosol particles, and therefore refer to the grown particles as droplets. Particle growth can, for various reasons, also occur in the solid or glassy states (Pöschl, 2001). In fact, it is possible that citric acid particles growing at low water and ethanol saturation ratios (see Sect. 4 below) are amorphous rather than liquid. Unfortunately there are no general theoretical methods available for describing solid or glassy particle growth in undersaturated vapors, and therefore we limit ourselves to considering deliquescent growth. However, it should be pointed out that chemical reactions between the particle material and the vapor may lead to growth factors differing from those given by the theory, especially if the reaction products are volatile.

The thermodynamics of aerosol growth in an undersaturated solvent vapor can be described using equations analogous to those accounting for the equilibrium of aqueous solution droplets in humid air. Thus, the saturation ratio of the solvent at which the solution droplets are in equilibrium can be written as

$S=a_{s} \exp \left(\frac{2 \sigma v_{s}}{k T r}\right)$

where $a_{s}$ is the activity of the solvent in the solution droplet, and the exponential term describes the Kelvin effect which increases the vapor pressure at the droplet surface due to the droplet curvature. The symbol $\sigma$ denotes the surface tension of the droplet, $v_{s}$ is partial molecular volume of the solvent, $k$ is the Boltzmann constant, $T$ is the temperature and $r$ is the droplet radius. The effect of the Kelvin term can be considered small if the diameter of the dry aerosol particle is above $100 \mathrm{~nm}$. In this paper we are dealing with $100 \mathrm{~nm}$ particles, and we therefore neglect the Kelvin term. The activity can be written as $a_{s}=\gamma_{s} x_{s}$ where $\gamma_{s}$ denotes the activity coefficient and $x_{s}$ the mole fraction of the solvent in the droplet. If there is no experimental equation available for the activity coefficient, it can in some cases be estimated. The simplest approximation is of course to assume that the liquid solution is ideal, i.e. $\gamma_{s}=1$. For $\mathrm{NaCl}$ and ammonium sulfate, we used water activities measured by Tang et al. (1986) and by Tang and Munkelwicz (1993), respectively.

The growth factor (GF) of the aerosol particle is defined as the diameter of the particle at saturation ratio $S$ divided by the diameter of the dry particle (particle at saturation ratio 0), and it can be expressed as (Swietlicki et al., 1999)

$G F=\left(\frac{\rho_{d}}{\rho_{s o l}}\left(1+\left(m M_{d}\right)^{-1}\right)\right)^{1 / 3}$,

where $\rho_{d}$ and $\rho_{s o l}$ are the densities of the dry particle and the solution droplet, respectively, $m$ is the molality of the solution and $M_{d}$ is the molar weight of the dissolved material. Experimental solution densities are not necessarily available for the systems under consideration; in those cases (all compounds in ethanol vapor and citric acid in water vapor) we apply the simple approximation $\rho_{s o l}=\left(1-x_{s}\right) \rho_{d}+x_{s} \rho_{s}$, where $\rho_{s}$ denotes the density of pure solvent. The solution densities and activities for $\mathrm{NaCl}$ and ammonium sulfate water droplets were calculated using formulas tabulated by Hämeri et al. (2001b) and Hämeri et al. (2000), respectively. Other values used in the calculations are summarized in the Table 2. All pure component densities and molar weights were obtained from the CRC Handbook of Chemistry and Physics (1995).

\section{Results and discussion}

In order to demonstrate that the new measurement principle is operational, we measured growth curves for four different substances in ethanol vapor. The selected substances were citric acid, adipic acid, sodium chloride and ammonium sulfate. The growth of the same substances in water vapor was also measured and the results for the inorganic 
a)

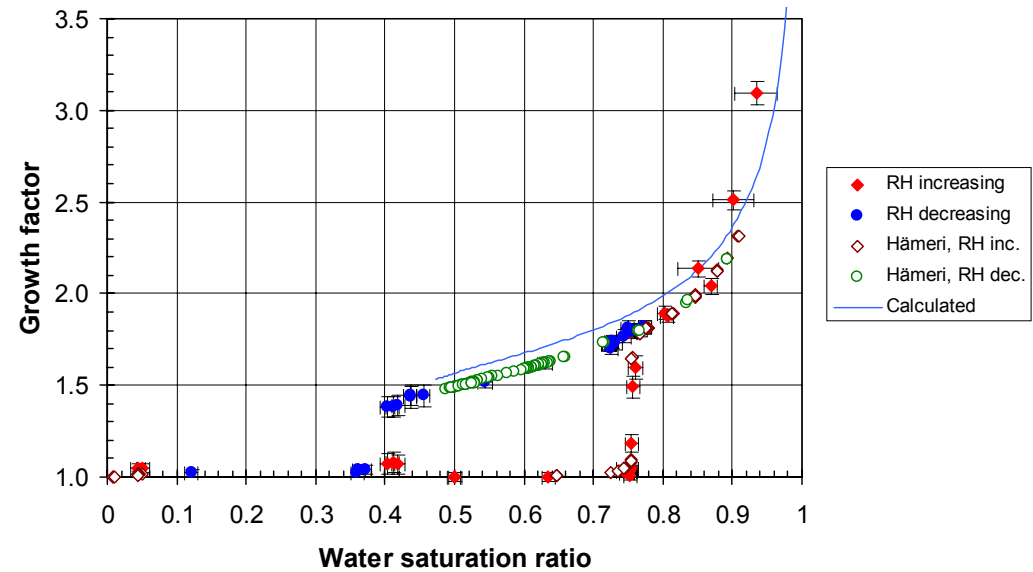

b)

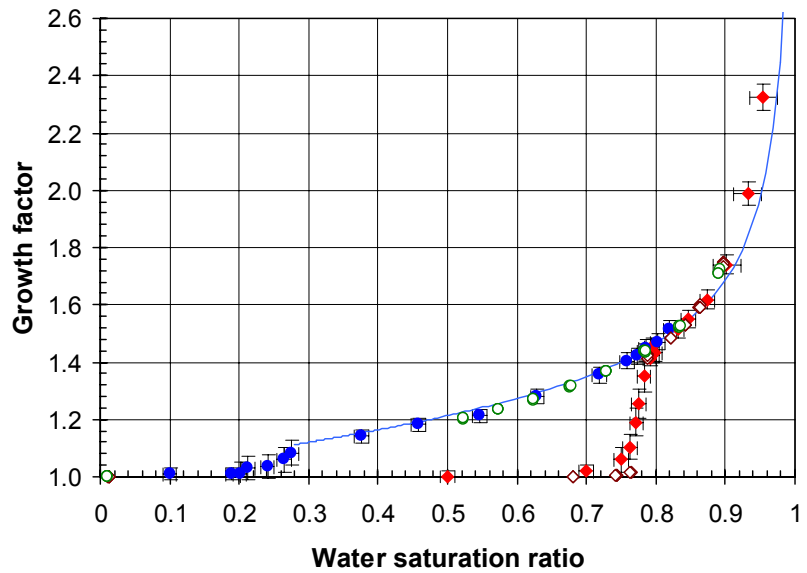

c)

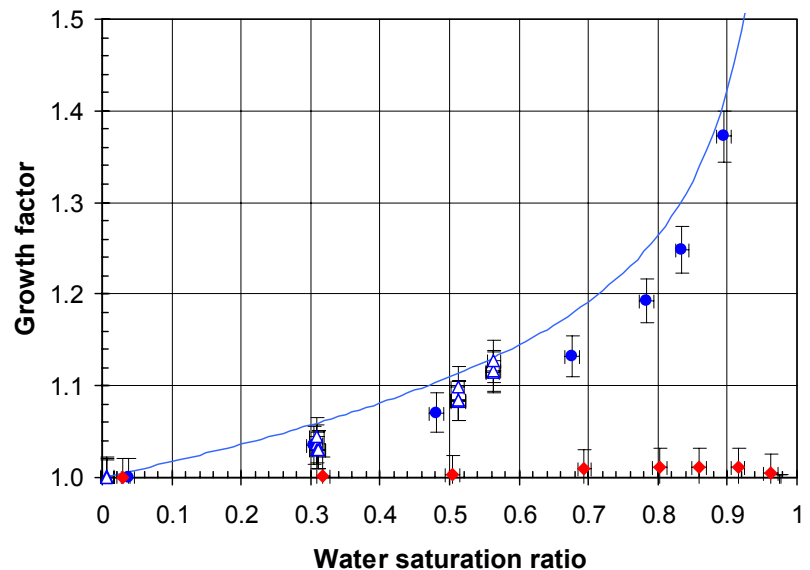

$\mathrm{RH}$ increasing

- $\mathrm{RH}$ decreasing

$\diamond$ Hämeri, RH inc.

- Hämeri, RH dec Calculated
- Citric acid

$\triangle$ Citric acid II

Calculated

- Adipic acid

Fig. 2. Growth factors (particle diameter change) as a function of water vapor saturation ratio, i.e. growth curves, for (a) sodium chloride, (b) ammonium sulfate, and (c) citric acid and adipic acid particles. Experimental growth curves with increasing and decreasing saturation ratios are plotted separately for sodium chloride (a) and ammonium sulfate (b) particles and compared with the experimental results by Hämeri et al. (2001b) and Hämeri et al. (2000), respectively. In addition, the data are compared with calculated growth curves (not for adipic acid). For citric acid, data points measured with a diffusion dryer before the DMA-1 are marked as Citric acid II. Error bars indicate accuracy of the measurements (typically $1 \%$-unit for vapor saturation ratio and $2 \%$ for growth factor).

salts were compared with results presented in the literature in order to demonstrate the reliability of the TDMA. Citric acid and adipic acid were chosen because they were expected to show different growth behavior especially in water vapor, as citric acid is highly soluble in water whereas adipic acid is only very slightly soluble (Saxena and Hildemann, 1996; Hämeri et al., 1998). In the atmosphere, citric acid is found as one of the most important organic components in sea-salt aerosols, whereas adipic acid is a typical representative of dicarboxylic acids found in organic aerosols (Saxena and Hildemann, 1996).

Figures $2 \mathrm{a}$ and $2 \mathrm{~b}$ show our measured growth curves, i.e. growth factors as a function of water vapor saturation ratio for sodium chloride and ammonium sulfate in water va- 
a)

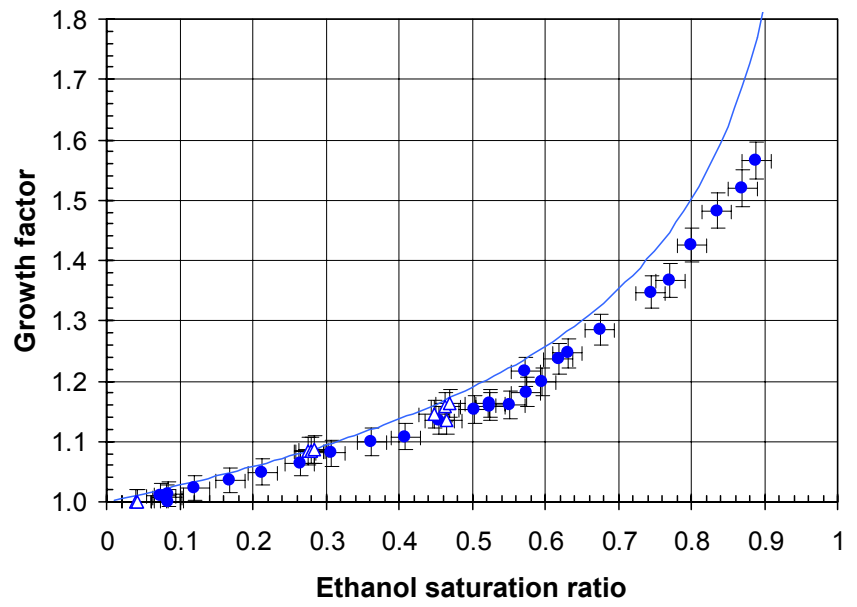

b)

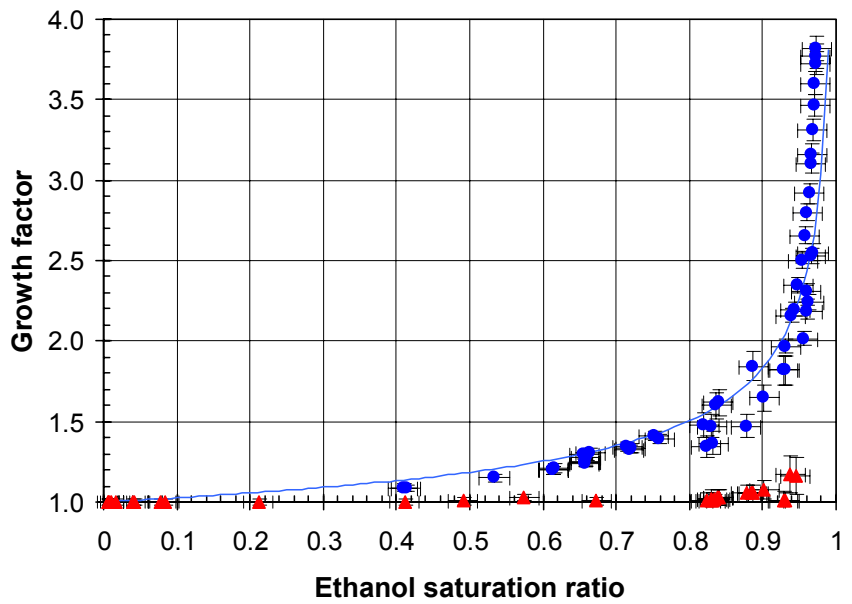

- Experimenta

$\triangle$ Exp. II Calculated

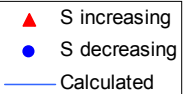

- $S$ decreasing Calculated
Fig. 3. Growth factors (particle diameter change) as a function of ethanol vapor saturation ratio, i.e. growth curves, for (a) citric acid, and (b) adipic acid particles. Experimental growth curves with increasing and decreasing saturation ratios are plotted separately for adipic acid particles (a). In addition, calculated growth curves for citric acid (a) and adipic acid (b) particles are shown. For citric acid, data points measured with a diffusion dryer before the DMA-1 are marked as Exp. II. Error bars indicate accuracy of the measurements (typically $2 \%$-unit for vapor saturation ratio and $2 \%$ for growth factor) por. The temperature of DMA- 2 was $23^{\circ} \mathrm{C}$ and the dry particle diameter was $100 \mathrm{~nm}$. To determine the hysteresis phenomenon (i.e. difference in deliquescence and recrystallization saturation ratios) of particle growth and evaporation, the growth curves were measured with both increasing RH (RH aerosol flow $<\mathrm{RH}$ sheath flow) and decreasing $\mathrm{RH}$ (RH aerosol flow $>$ deliquescence $\mathrm{RH}$ of the particles). The solid lines show theoretical growth curves based on water activities measured by Tang et al. (1986) for $\mathrm{NaCl}$ and by Tang and Munkelwicz (1993) for ammonium sulfate. The data are also compared with experimental results for $50 \mathrm{~nm}$ particles (Hämeri et al., 2000, 2001b). Our measured deliquescence points are at water saturation ratios $(S)$ of 0.75 for sodium chloride and 0.79 for ammonium sulfate, which compare very well with the respective literature values of 0.753 and 0.799 at $25^{\circ} \mathrm{C}$ (Tang and Munkelwicz, 1993). This indicates that we have determined the relative humidity in our experiments rather accurately. At $S=0.8$, the measured growth factors are 1.9 and 1.46 for sodium chloride and ammonium sulfate particles, respectively (see Table 3), which are similar to the literature values of 2 and 1.5, respectively (Mc-
Murry and Stolzenburg, 1989; Svenningsson, 1997; Hansson et al., 1998). At higher water saturation ratios $(S>0.85)$, the growth factors of some data points of sodium chloride seem to be higher than those of the calculated and previously measured. Temperature data measured for those point shows that the temperature of the excess air was about $0.6^{\circ} \mathrm{C}$ higher than that of the temperature bath $\left(23^{\circ} \mathrm{C}\right)$. We suppose that the temperature of air flow inside DMA-2 was close to that of the temperature bath, i.e. lower than at excess air, which indicates that saturation ratio inside the DMA-2 may have been about $1-3 \%$-units higher than the measured value at the excess flow.

Figure 2c shows our experimental growth curve for citric acid particles in water vapor. Some experiments were measured using the diffusion dryer before the DMA-1 and they are marked as Citric acid II. The particles grow monotonously with increasing saturation ratios and no sharp deliquescence point is observed at $S>0.3$. This indicates that the growth curve is reversible, i.e. no hysteresis loop would be seen if measurements were carried out with decreasing saturation ratios. Based on literature values of cit- 
ric acid solubility in water and water activity of the saturated solution (Apelblat et al., 1995), we would have expected a deliquescence point at saturation ratios between 0.8 and 0.9. Citric acid has a tendency to form a monohydrate $\left(\mathrm{HOC}\left(\mathrm{CH}_{2} \mathrm{CO}_{2} \mathrm{H}\right)_{2} \mathrm{CO}_{2} \mathrm{H} \cdot \mathrm{H}_{2} \mathrm{O}\right)$ at temperatures below 309 $\mathrm{K}$. The growth behavior seen here is similar as that observed with other hydrating substances (Cohen et al., 1987; Peng and Chan, 2001). A possible explanation for the reversible growth curve is that although we typically dry the dispersion aerosol at about $7 \%$ relative humidity (at $1-4 \%$ relative humidity in the experiments with the diffusion dryer), not all of the water is evaporated from the particles (Cohen et al. (1987) refer to glassy solid solutions), and as a result the particles will take up more water as the relative humidity increases. The theoretical growth curve is based on the assumption of solution ideality and was calculated using estimated liquid densities. The predicted growth factors are clearly higher than the measured values, which is no surprise considering the simplicity of the assumptions.

We also measured the behavior of adipic acid particles as a function of water saturation ratio as shown in Fig. 2c. As expected, we see no growth at $S<0.96$.

The starting point for our investigation of particle treatment using organic vapors was to measure the growth factors of sodium chloride and ammonium sulfate in ethanol. As with adipic acid in water vapor, we saw no growth in decreasing saturation ratio measurements at $S<0.93$. In these experiments, the aerosol flow was saturated or nearly saturated with ethanol prior to entering DMA-2. Because of the extremely poor solubility of these salts in ethanol, one would not expect any growth at saturation ratios below unity.

Figure 3a shows the growth curve of citric acid particles in ethanol vapor. Some extra points were measured with the diffusion dryer before the DMA-1 (marked as Exp. II). Similarly as with water vapor, the particles grow monotonously with increasing saturation and no stepwise deliquescence can be seen indicating that the growth is reversible. Citric acid is well soluble in ethanol; the Merck Chemical Database (ChemDAT, 2000) gives a value of $419 \mathrm{~g} / 1\left(25^{\circ} \mathrm{C}\right)$ for monohydrate, whereas our own measurement gave a solubility of $690 \mathrm{~g} / \mathrm{l}\left(24^{\circ} \mathrm{C}\right)$. Although these two values are quite different, neither is big enough to lead one to expect a reversible growth curve instead of a hysteresis loop. It may be the case that ethanol is taken up by the particles already at saturation ratios below unity because the particles contain water, as speculated above. We have also calculated a theoretical growth curve assuming that ethanol and citric acid form an ideal solution and that the droplet contains no water. The agreement is somewhat better than with citric acid in water vapor, but the growth is still overestimated especially at higher saturation ratios.

Figure $3 b$ shows the growth curve of adipic acid in ethanol measured with increasing and decreasing saturation ratios. Because of the reasons outlined in Sect. 2.1 above, the increasing saturation ratio measurements were limited to $S<$
Table 3. Growth factors for sodium chloride, ammonium sulfate, citric acid and adipic acid particles in water and ethanol vapor at saturation ratios $(S)$ of 0.8 and 0.9 . Uncertainty of growth factor values was estimated from accuracies to determine saturation ratio (about 1\%-unit for water and 2\%-units for ethanol) and particle size (about 2\%).

\begin{tabular}{llcc}
\hline Substance & $\begin{array}{l}\text { Solvent } \\
\text { vapor }\end{array}$ & $\begin{array}{c}\text { Growth factor } \\
\text { at } S=0.8\end{array}$ & $\begin{array}{c}\text { Growth factor } \\
\text { at } S=0.9\end{array}$ \\
\hline Sodium chloride & water & $1.9 \pm 0.05$ & $2.5 \pm 0.3$ \\
& ethanol & $1.0 \pm 0.03$ & $1.0 \pm 0.03$ \\
Ammonium sulfate & water & $1.46 \pm 0.02$ & $1.74 \pm 0.05$ \\
& ethanol & $1.0 \pm 0.03$ & $1.0 \pm 0.03$ \\
Citric acid & water & $1.21 \pm 0.02$ & $1.4 \pm 0.05$ \\
& ethanol & $1.42 \pm 0.05$ & $1.6^{*} \pm 0.1$ \\
Adipic acid & water & $1.0 \pm 0.02$ & $1.0 \pm 0.02$ \\
& ethanol & $1.0 \pm 0.03$ & $1.7^{\dagger} \pm 0.2$ \\
\hline
\end{tabular}

* extrapolated

${ }^{\dagger}$ decreasing saturation ratio

0.95 and the decreasing saturation ratio measurements to $S<0.98$. The results indicate that the deliquescence takes place at around $S>0.95$, and possibly closer to $S=0.95$ than to $S=1.0$. We have two reasons to believe that this is the case. First, a measurement of the solubility of adipic acid in ethanol at $298 \mathrm{~K}$ gave a value of 11.15 grams per 100 gram of solution, which corresponds to an acid mole fraction of 0.038 . With an ethanol activity coefficient of unity, this would correspond to a deliquescence saturation ratio of 0.96 . Second, as can be seen from Fig. 3b, the growth factors at the two highest increasing saturation ratios are somewhat above unity, a common feature seen just before the deliquescence transition in almost all experimental studies.

Fig. 3b also shows hysteresis behavior for the growth of adipic acid particles in ethanol vapor. The hysteresis loop encompasses quite a wide range of saturation ratios, and it seems that the recrystallization point is below $S=0.4$. The data points at the upper branch of the hysteresis loop, especially at the steep portion of the curve, are slightly unreliable due to the difficulty to produce and measure high ethanol saturation ratios reliably. To determine the curve (as well as the deliquescence point) more accurately, a more stable ethanol treatment system needs to be to developed.

As with citric acid, we calculated a growth curve for adipic acid particles in ethanol vapor assuming solution ideality. In this case, the agreement with measurements is reasonable. However, it is possible that this is due to cancellation of errors made in assuming ideal solution and in estimating solution densities.

The growth factors for sodium chloride, ammonium sulfate, citric acid and adipic acid particles in water and ethanol vapors at saturation ratios of 0.8 and 0.9 are shown in Ta- 
ble 3. In summary, we found the growth behavior of the various substances in the two vapors to be more or less what we expected, with the exception of citric acid, which quite surprisingly showed reversible growth in ethanol vapor instead of a deliquescence transition and a hysteresis loop. We believe that our results demonstrate that the OTDMA, operated in parallel with an HTDMA, can be used to categorize single-component particles according to Table 1 . Whether the new instrument proves useful in studying the composition of multicomponent aerosols remains to be seen. It is well known that the growth factors of internally mixed aerosols in humid air are not necessarily linear averages of the growth factors of the individual species (see e.g., Cruz and Pandis, 2000). However, it has been shown (Hämeri et al., 1998) that the water vapor growth factors of mixed particles of ammonium sulfate and very slightly water soluble organic species can in fact be calculated as if the organic species was completely inert. Our preliminary laboratory and smog chamber measurements indicate that such particles behave in an opposite manner in the OTDMA; their growth factors can be calculated if the growth factor of the pure organic species in ethanol vapor is known and the inorganic salt is assumed inert. We are therefore optimistic about the usefulness of the OTDMA in characterizing also internally mixed atmospheric particles.

\section{Conclusions}

We have developed and constructed a novel instrument to characterize the organic composition of single aerosol particles. The operation method of the instrument is based on organic vapor interaction with aerosol particles. The new instrument has been named the Organic Tandem Differential Mobility Analyzer (OTDMA). We have tested the OTDMA method for both inorganic and organic aerosol particles and compared the results with hygroscopicity TDMA results. Growth curves of sodium chloride, ammonium sulfate, citric acid and adipic acid particles have been measured both in ethanol and water vapors as a function of saturation ratio.

Measurements in water vapor show that sodium chloride and ammonium sulfate as well as citric acid particles grow at water saturation ratios $(S)$ of 0.8 and above, whereas adipic acid particles do not grow at $S<0.96$. For sodium chloride and ammonium sulfate particles, a deliquescence point is observed at $S=0.75$ and $S=0.79$, respectively, which are very close to literature values. For citric acid no clear deliquescence point is found and the particles start to grow monotonously with increasing saturation ratios already at low saturation ratios. This behavior is similar as has been observed with some other substances which have a tendency to form hydrates.

Sodium chloride and ammonium sulfate behave differently in ethanol vapor than in water vapor as no growth can be seen even with particles which have first experienced saturated conditions and are then brought to a final ethanol saturation ratio of 0.93 . The growth behavior of citric acid particles is similar in ethanol vapor as in water vapor in that the particles grow monotonously with increasing saturation ratios and no stepwise deliquescence can be observed. Adipic acid particles, on the other hand, behave differently than in water vapor, as the deliquescence takes place at around $S=0.95$ in ethanol vapor, and a hysteresis loop is observed. It is probable that many organic substances behave in this manner; even if their solubility in ethanol is substantial when expressed on mass basis, it may be quite limited when expressed on mole fraction basis, which means that the deliquescence will occur at rather high saturation ratio. It may therefore be advisable to measure decreasing saturation ratios when the OTDMA is used in field studies; it is likely that more organic substances will be detected if the $S$ of the aerosol flow is close to unity rather than below that of the sheath flow.

In summary, we have demonstrated that the working principles of the OTDMA are operational for single-component aerosols. Furthermore, the results indicate that the OTDMA method may prove useful in determining whether aerosol particles contain organic substances, especially if the OTDMA is operated in parallel with a HTDMA, as the growth of many substances is different in ethanol and water vapors. Different organic solvents can also be used instead of ethanol. The developed method will be used to study the origin and chemical characteristics of rural and urban aerosols in field studies.

Acknowledgements. We thank Arto Niva for carrying out the adipic acid solubility measurement and Teemu Toivanen for his help during the experiments. This work was supported by the Academy of Finland (project 50623) and EU $5^{\text {th }}$ Frame Programme through the project Origin and Formation of Secondary Organic Aerosol (OSOA).

\section{References}

Ahonen, P. P., Joutsensaari, J., Richard, O., Tapper, U., Brown, D. P., Jokiniemi, J. K., and Kauppinen, E. K.: Mobility size development and the crystallization path during aerosol decomposition synthesis of $\mathrm{TiO}_{2}$ particles, J. Aerosol Sci., 32, 615-630, 2001.

Apelblat, A., Dov, M., Wisniak, J., and Zabicky, J.: The vapour pressure of water over saturated aqueous solutions of malic, tartaric, and citric acids at temperatures from $288 \mathrm{~K}$ to $323 \mathrm{~K}$, J. Chem. Thermodynamics, 27, 35-41, 1995.

ChemDAT, the Merck Chemical Database, CD-ROM, Merck KGaA, Darmstadt, Germany, 2000.

Cohen, M. D., Flagan, R. C., and Seinfeld, J. H.: Studies of concentrated electrolyte solutions using the electrodynamic balance. 1. water activities for single-electrolyte solutions, J. Phys. Chem., 91, 4563-4574, 1987.

CRC Handbook of Chemistry and Physics, $76^{\text {th }}$ edition, CRC Press, New York, 1995. 
Cruz, C. N. and Pandis, S. N.: Deliquescence and hygroscopic growth of mixed inorganic-organic atmospheric aerosol, Environ. Sci. Technol., 34, 4313-4319, 2000.

Hansson, H.-C., Rood, M. J., Koloutsou-Vakakis, S., Hämeri, K., Orsini, D., and Wiedensohler, A.: $\mathrm{NaCl}$ aerosol particle hygroscopicity dependence on mixing with organic compounds, J. Atmos. Chem., 31, 321-346, 1998.

Hämeri, K., Charlson, R. J., Hansson, H.-C., and Jacobson, M.: Hygroscopic properties of ammonium sulfate aerosol particles mixed with slightly soluble organic compound, J. Aerosol Sci., 29 (Suppl. 1), S587-S588, 1998.

Hämeri, K., Väkevä, M., Hansson, H.-C., and Laaksonen, A.: Hygroscopic growth of ultrafine ammonium sulphate aerosol measured using an ultrafine tandem differential mobility analyser, J. Geophys. Res., 105, 22 231-22 242, 2000.

Hämeri, K., Väkevä, M., Aalto, P. P., Kulmala, M., Swietlicki, E., Zhou, J., Seidl, W., Becker, E., and O'Dowd, C. D.: Hygroscopic and $\mathrm{CCN}$ properties of aerosol particles in boreal forest, Tellus, 53B, 359-379, 2001a.

Hämeri, K., Laaksonen, A., Väkevä, M., and Suni. T.: Hygroscopic growth of ultrafine sodium chloride particles, J. Geophys. Res., 106, 20 749-20 757, 2001b.

Joutsensaari, J., Ahonen, P. P., Kauppinen, E. I., Brown, D. P., Lehtinen, K. E. J., Jokiniemi, J. K., Pauwels, B., and Van Tendeloo, G.: Aerosol synthesis of fullerene nanocrystals in controlled flow reactor conditions, J. Nanoparticle Res., 2, 53-74, 2000.

Kerminen, V.-M.: The effects of particle chemical character and atmospheric processes on particle hygroscopic properties, J. Aerosol Sci., 28, 121-132, 1997.

Knutson, E. O. and Whitby, K. T.: Aerosol classification by electric mobility: apparatus, theory and applications, J. Aerosol Sci., 6, 443-451, 1975.

Liu, P. Y. H., Pui, D. Y. H., Whitby, K. T., Kittelson, D. B., Kousaka, Y., and McKenzie, R. L.: The aerosol mobility chromatograph: a new detector for sulfuric acid aerosols, Atmos. Environ., 12, 99-104, 1978.

McMurry, P. H. and Stolzenburg, M. R.: On the sensitivity of particle size to relative humidity for Los Angeles aerosols, Atmos. Environ., 23, 497-507, 1989.

Novakov, T. and Penner, J. E.: Large contribution of organic aerosols to cloud-condensation-nuclei concentrations, Nature, 365, 823-826, 1993.

Peng, C. and Chan, C. K.: The water cycles of water-soluble organic salts of atmospheric importance, Atmos. Environ., 35, 11831192,2001
Pöschl, U.: Interactive comment on "A novel tandem differential mobility analyzer with organic vapor treatment of aerosol particles" by “J. Joutsensaari et al.", Atmos. Chem. Phys. Discuss., 1, S56-S57, 2001.

Reischl, G. P.: Measurement of ambient aerosols by the different mobility analyzer method: concepts and realization criteria for the size range between 2 and $500 \mathrm{~nm}$, Aerosol Sci. Technol., 14, 5-24, 1991.

Saxena, P. and Hildemann, L. M.: Water-soluble organics in atmospheric particles: A critical review of the literature and application of thermodynamics to identify candidate compounds, J. Atmos. Chem., 24, 57-109, 1996.

Schmeling, T. and Strey R.: Equilibrium vapor pressure measurements for the n-alcohols in the temperature range from $-30^{\circ} \mathrm{C}$ to $+30^{\circ} \mathrm{C}$, Ber. Bunsenges. Phys. Chem., 87, 871-874, 1983 .

Schultz, G.: General Eastern, USA, personal communication, 2000.

Svenningsson, B.: Hygroscopic growth of atmospheric aerosol particles and its relation to nucleation scavenging in clouds, Doctoral thesis, Department of Nuclear Physics, University of Lund, Sweden, 1997.

Svenningsson, B., Hansson, H.-C., Martinsson, B., Wiedensohler, A., Swietlicki, E., Cederfelt, S.-I., Wendisch, M., Bower, K. N., Choularton, T. W., and Colvile, R. N.: Cloud droplet nucleation scavenging in relation to the size and hygroscopic behaviour of aerosol particles, Atmos. Environ., 31, 2463-2475, 1997.

Swietlicki, E., Zhou, J., Berg, O. H., Martinsson, B. G., Frank, G., Cederfelt, S.-I., Dusek, U., Berner, A., Birmili, W., Wiedensohler, A., Yuskiewicz, B., and Bower, K. N.: A Closure study of sub-micrometer aerosol particle hygroscopic behaviour, Atmos. Res., 50, 205-240, 1999.

Tang, I. N. and Munkelwicz, H. R.: Composition and temperature dependence of the deliquescence properties of hygroscopic aerosols, Atmos. Environ., 27A, 467-472, 1993.

Tang, I. N., Munkelwicz, H. R., and Wang, N.: Water activity measurements with single suspended droplets: The $\mathrm{NaCl}-\mathrm{H}_{2} \mathrm{O}$ and $\mathrm{KCl}-\mathrm{H}_{2} \mathrm{O}$ systems, J. Colloid Interface Sci., 114, 409-415, 1986.

Winklmayr, W., Reischl, G. P., Lindner, A. O., and Berner, A.: A new electromobility spectrometer for the measurement of aerosol size distributions in the size range from 1 to $1000 \mathrm{~nm}$, J. Aerosol Sci., 22, 289-296, 1991.

Zhang, X. Q., McMurry, P. H., Hering, S. V., and Casuccio, G. S.: Mixing characteristics and water content of submicron aerosols measured in Los Angeles and at the Grand Canyon, Atmos. Environ., 27A, 1593-1607, 1993. 